\title{
Communication of Career Pathways Through Associate Degree Program Web Sites: A Baseline Assessment
}

\author{
Ellen A Becker PhD RRT RRT-NPS RPFT AE-C FAARC and Jenny Vargas MSc RRT RRT-NPS
}

\begin{abstract}
BACKGROUND: The American Association for Respiratory Care sponsored a series of conferences that addressed the competency of the future workforce of respiratory therapists (RTs). Based upon the findings from those conferences, several initiatives emerged that support RTs earning a baccalaureate (or bachelor's) degree. The objective of this study was to identify the ways that associate degree programs communicate career pathways toward a baccalaureate degree through their Web sites. METHODS: This cross-sectional observational study used a random sample of 100 of the 362 associate degree programs approved by the Commission on Accreditation for Respiratory Care. Data were collected from 3 specific categories: demographic data, baccalaureate completion information, and the Web page location for the program. The presence of statements related to any pathway toward a bachelor's degree, transfer credits, articulation agreements, and links for baccalaureate completion were recorded. The descriptive statistics in this study were reported as total numbers and percentages. RESULTS: Of the 100 programs in the random sample, only 89 were included in the study. Only $39(44 \%)$ programs had links on their program Web site that had any content related to bachelor's degrees, $16(18 \%)$ identified college transfer courses toward a bachelor's degree, and 26 (29\%) programs included baccalaureate articulation agreements on their Web site. CONCLUSIONS: A minority of associate degree programs communicated career pathway information to their prospective and current students through program Web sites. An informative Web site would make the path more transparent for entry-level students to meet their future educational needs as their careers progress. Key words: career pathways; associate degree; bachelor's/baccalaureate degree; respiratory therapist education; professional education. [Respir Care 2018;63(10):1207-1213. () 2018 Daedalus Enterprises]
\end{abstract}

\section{Introduction}

Respiratory therapists (RTs) receive their entry-level education through programs offered at 2-y and 4-y institutions. Over the past 15 years, several professional organizations have addressed advances in respiratory care education. In 2003, the American Association for Respiratory Care (AARC), the Commission on Accreditation for

Dr Becker is affiliated with the Department of Cardiopulmonary Sciences Rush University, Chicago, Illinois. Ms Vargas is affiliated with Adventist Hinsdale Hospital, Respiratory Care Department Hinsdale, Illinois.

Correspondence: Ellen Becker PhD RRT RRT-NPS RPFT AE-C FAARC, Rush University, 600 S. Paulina Street, Chicago, IL 60612. E-mail: ellen_becker@rush.edu.

DOI: $10.4187 /$ respcare. 06116
Respiratory Care (CoARC), and the National Board for Respiratory Care (NBRC) published the Tripartite Statement of Support (https://www.aarc.org/wp-content/uploads/ 2017/03/issuepaper_tripartite.pdf, Accessed December 17, 2017). This document states that obtaining the registered respiratory therapist credential should be the standard for RTs and encourages advanced levels of education for all RTs. It also highlights the need for employers to develop career ladders that facilitate RTs' abilities to utilize their higher education. In that same year, the AARC White Paper on baccalaureate and graduate respiratory therapy education was published. The White Paper stated that it is very difficult to achieve competency in the respiratory care field with a 2 -y program. ${ }^{1}$

Further support for baccalaureate entry-level education arose in a series of 3 conferences sponsored by the AARC that aimed to ensure the competency of the future RT workforce. ${ }^{2-4}$ The second conference identified the spe- 
cific competencies needed for future entry-level RTs. ${ }^{3}$ Among the outcomes of the third conference was that entry-level education should move to the baccalaureate degree. It should be noted that an opposing view was also

\section{See the Related Editorial on Page 1316}

expressed. ${ }^{4}$ More recently, a multi-stakeholder task force evaluated the competencies in the second conference and identified those that should be addressed during entrylevel education and those that can be developed after graduation (http://www.aarc.org/education/educator-resources/ competencies-entry-respiratory-therapy-practice, Accessed December 17, 2017). This task force recommended that education continue after graduation to learn all of the necessary competencies. Recommendations to move toward baccalaureate entry-level education also emerged in the 2016 Respiratory Therapist Education Position Statement, which mentions that new entry-level respiratory care programs should award a minimum of a baccalaureate degree (http:// www.aarc.org/resources/professional-documents/positionstatements, Accessed December 19, 2017).

The CoARC accredits respiratory care programs and tracks data on program types. There has been growth in the number of baccalaureate entry-level programs from 51 in 2011 to 65 in 2016, representing a $27 \%$ change. ${ }^{5}$ This change demonstrates that the educational market is responding to clinical needs.

Literature targeting the need for baccalaureate degrees and why associate degree graduates pursue them is limited. A study in several Pennsylvania hospitals explored the relationship between the nurses' level of education and the mortality rates in several units. ${ }^{6}$ They hypothesized that advancing the education of practicing nurses would lead to better patient care outcomes and lower mortality rates. Data from general, orthopedic, and vascular surgery units were analyzed. Survey responses that provided data regarding educational composition, staffing, and other characteristics indicated that a $10 \%$ increase in of the proportion of nurses with higher degrees decreased the risk of mortality and of failure to rescue by a factor of $4 \%$. Therefore, the baccalaureate level of education for registered nurses was associated with lower mortality. The same results may occur with RTs.

The reasons given by graduates with Associate of Applied Science (AAS) degrees from technical or industrial fields for pursuing baccalaureate degrees has been explored. ${ }^{7}$ The study sample came from a single 4-y degree completion program. Achieving a personal goal was the top reason for pursuing an advanced degree, and professional development and job advancement ranked as second and third. An increased salary was ranked lower. ${ }^{7}$ Again, the perspectives of RTs are unknown.

\section{QUICK LOOK}

\section{Current knowledge}

Two-year universities facilitate career pathways for associate degree graduates to complete baccalaureate degrees. The ease of transferring from an associate degree to a baccalaureate degree program is enhanced through clear communication of transfer credits and articulation agreements. Transfer credits and articulation agreements are often poorly communicated to students. Close collaboration among 2-y and 4-y programs enhances the baccalaureate transfer process.

\section{What this paper contributes to our knowledge}

Few associate degree respiratory care programs promote career pathway information on their program Web sites. Program Web sites often lacked reference to pursuing a baccalaureate degree and information about transfer credits and articulations agreements. Resources for respiratory care programs to collaborate on career pathways are available. Respiratory therapists need to know the differences in baccalaureate degree type (Bachelor of Science vs. Bachelor of Applied Science).

The route to a baccalaureate degree can take 2 paths. The most direct route is to enroll in an entry-level baccalaureate degree program. Alternatively, RTs can utilize a degree-advancement program to complete a baccalaureate degree after graduating from an associate degree program. The AARC supports both pathways. Regarding degree advancement, the AARC has a goal for $80 \%$ of RTs to have achieved or be actively working toward a baccalaureate degree by the year 2020 (https://www.aarc.org/aarc-bodsets-80-bachelor-degree-goal-by-2020, Accessed December 19, 2017). In addition, the Respiratory Therapist Education Position Statement supports articulation agreements to help students with an associate's degree move forward on a career pathway to a baccalaureate (or bachelor's) degree (http://www.aarc.org/resources/professionaldocuments/position-statements, Accessed December 19, 2017). Currently, we do not know how well entry-level programs at the Associate of Science (AS) or AAS degree level encourage their prospective students to see their entry-level programs as the first step on a career pathway toward a baccalaureate degree. Therefore, this descriptive study was designed to determine the proportion of AS and AAS degrees in respiratory care that encourage a pathway to a baccalaureate degree. Specifically, this study evaluated how well respiratory care associate degree programs promoted a career pathway toward a baccalaureate degree through their program Web sites. 


\section{Communication of Career Pathways by Associate Programs}

\section{Methods}

This cross-sectional observational study evaluated the Web sites of a random sample of 100 associate degree programs that held CoARC accreditation on December 31, 2015.

\section{Data Collection}

The study variables were collected using an online form created in REDCap (ProQuest, Ann Arbor, Michigan), a secure Web-based research database. The data collected fell into 3 categories: demographic data, baccalaureate completion information, and the Web page location for the bachelor's degree information. The demographic section included the name of the institution, the state location, prerequisite credit requirements, and total program credit requirements. When a range of credits was listed, the lowest value in the range was recorded. Prerequisite courses were considered to be courses that were required prior to enrolling in respiratory care courses. The degree categories included were AS, AAS, Associate of Occupational Studies, and Associate of Science Transfer degree. Only programs that had active CoARC accreditation in the fall of 2016 and plans to enroll students in 2017 were included in this study.

The baccalaureate completion information addressed statements related to baccalaureate completion, transfer credits, the presence of articulation agreements, and any links for baccalaureate completion. If present, college degree courses that could be transferred and the total transfer credits were recorded. Yes or no responses were recorded for reference to any narrative that related to the desire or potential of RTs to complete bachelor's degree, information about transfer credits to a baccalaureate degree, bachelor's degree articulation agreements on Web site, and links to baccalaureate completion programs. The location of bachelor's degree information on the program Web site was recorded as top, middle, bottom, or subfolder.

\section{Study Procedures}

The list of accredited AS, AAS, Associate of Occupational Studies, and Associate of Science Transfer programs from the outcomes data from 2015 CoARC Annual Report of Current Status for Entry into Respiratory Care Professional Practice Programs ${ }^{8}$ were transferred into Excel (Microsoft, Redman, Washington) and numbered from 1 to 362. Next, 100 random numbers were generated using the Excel random numbers function, and this list of 100 random numbers were matched to the numbered program list to identify the study sample. Data were collected from only 1 program when an institution offered programs at several locations and had identical Web sites.
The Web site addresses were retrieved from the CoARC Web site. Two reviewers evaluated the program Web pages and entered the data into REDCap. Consensus was obtained when findings differed. Data from REDCap was exported into SPSS v. 19 (SPSS, Chicago, Illinois) for analysis. Emails were sent to the program directors if information on the program Web site was unclear or contradictory to the 2015 CoARC report. ${ }^{8}$

\section{Data Analysis}

Numbers and percentages were reported for state location, reference to bachelor's degrees, college transfer credit, presence of baccalaureate articulation agreements, links to bachelor's degree completion programs, and location of information on program Web site. The study sample was evaluated using SPSS v. 19 for representativeness by comparing it to the population of 362 programs for regional distribution and degree granted. Program locations by state were compared using the regional distribution from the 2014 AARC Human Resources Survey. ${ }^{9}$ The proportions of AS and AAS degree programs were also compared. A Pearson's chi-square tested at $\alpha=.05$ was used to determine the representativeness of the programs from the sample to the population.

\section{Results}

A total of 100 programs from the 2015 CoARC report were evaluated, of which only 89 were included. There were 8 programs with duplicate Web page information, 2 programs that were not enrolling a new student cohort in 2017, and 1 program that offered a bachelor's degree (Fig. 1). The sample included the following degree programs: 35 AS, 62 AAS, 1 Associate of Occupational Studies, 1 Associate of Science Transfer, and 1 bachelor's degree. There was no difference in the ratio of AS and AAS degree programs in study sample compared to the ratio in the 2015 CoARC report data $(P=.54)$. With regard to the regional distribution of programs in the study sample (data from CoARC report in parentheses), there were 15 (49) programs in the Northeast, 23 (89) programs in the Midwest, 45 (152) programs in the South, and 17 (72) programs in the West. A Pearson chi-square revealed that there was no difference between the regional distribution of programs in the study sample and the CoARC population data $(P=.87)$.

Only $39(44 \%)$ programs had content on their program Web site that relayed information about bachelor's degrees. Of the 89 programs surveyed, only 15 (17\%) included any RT baccalaureate completion language. Two (5\%) programs that offered AAS degrees had language on the Web site about not being the right program choice if the student's goal was to earn a bachelor's degree 


\section{Communication of Career Pathways by Associate Programs}

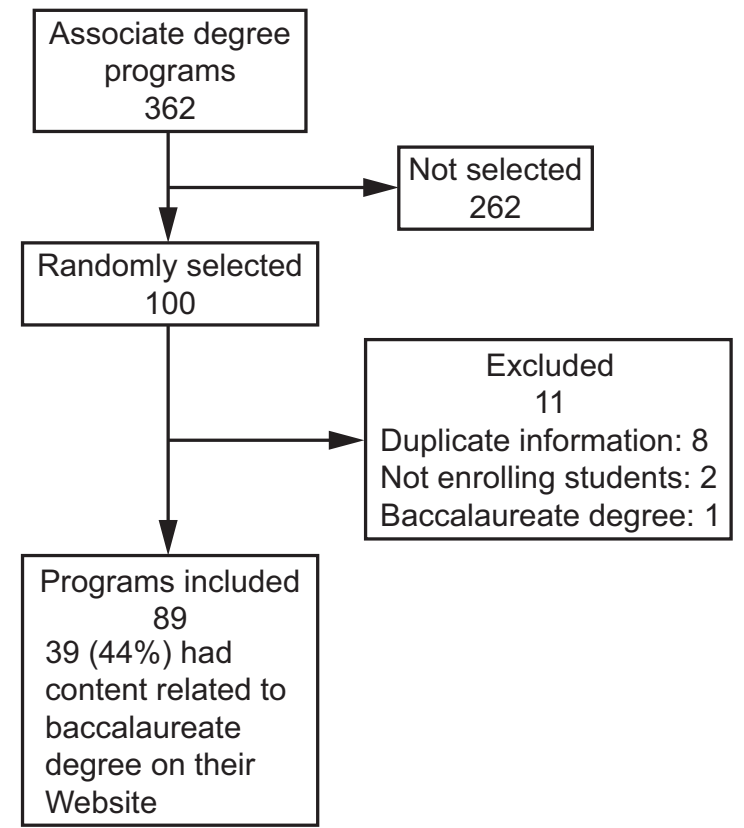

Fig. 1. Flow chart.

later. A total of $16(18 \%)$ programs identified college transfer courses for a bachelor's degree on either their program or college Web site. Frequently the college transfer information lacked the detail that program graduates need to project total transfer credits. There were 26 (29\%) programs that had links to baccalaureate articulation agreements on their Web site. Five programs provided information on both articulation agreements and transfer credits.

With regard to the location of the information related to a bachelor's degree on the program Web site, $5(6 \%)$ were at the top, $7(8 \%)$ were in the middle, $6(7 \%)$ were at the bottom, and $21(24 \%)$ were in a subfolder. None of the program Web sites made reference to the AARC goal of having $80 \%$ of RTs holding or working toward a bachelor's degree by 2020 .

\section{Discussion}

The number of students across all degree majors entering 2-y institutions who had a goal of earning a baccalaureate degree increased from $40 \%$ in the 1970 s and $1980 \mathrm{~s}^{10}$ to $70 \%$ in the $1990 \mathrm{~s}^{11}$ and to $80 \%$ in the $2000 \mathrm{~s} .{ }^{12}$ The more recent findings align with the AARC goal for $80 \%$ of RTs to either hold or be working toward a bachelor's degree by 2020. Despite this support for earning baccalaureate degrees, only $44 \%$ of programs in the current study sample referred to the baccalaureate degree topic on their program Web sites. This value is low, considering the role that 2-y institutions have in providing career pathways for their graduates to complete bachelor degrees, ${ }^{13}$ and the role that
Web sites play in marketing programs for colleges and universities to prospective students. ${ }^{14}$

\section{Impact of Associate Degree Type}

The type of associate degree awarded by the respiratory care program directly affects credit transfer. The AS degree awarded by 2-y colleges is an indicator that the student is prepared for upper-division courses in a 4-y institution, ${ }^{15}$ and all or most credits transfer. In contrast, approximately one third of the general education courses for the AAS degree transfer to $4-y$ institutions ${ }^{16}$ because AAS programs were designed as terminal degrees, not with transfer in mind. ${ }^{17,18}$ Thus, it is more difficult for AAS graduates to transfer as many of their credits to most baccalaureate degree programs ${ }^{19}$ because of their vocational focus. ${ }^{16}$ As a result, AAS graduates have a less efficient pathway to earn their bachelor's degree. ${ }^{7} \mathrm{Be}$ tween 2011 and 2016, 61\% of respiratory care programs moved from an AS degree to an AAS degree, ${ }^{5}$ which could make it increasingly difficult for graduates to transfer their degree credits. The shift from AS to AAS degrees resulted from the growing RT educational content. To address the increased content, programs increased their total credit hours to as high as 99 semester-hour credits. States observed this "credit creep" and responded by limiting the total credits for an associate degree to around 60 credit hours. Programs redesigned their curricula to blend RTapplied content into what were previously academic courses and offered AAS degrees instead.

Presently, there are no data on the baccalaureate completion rates for AS and AAS respiratory care graduates. However, data on bachelor's completion rates across all AS versus AAS degrees is mixed. A higher completion rate for AS degree graduates has been shown in some studies, ${ }^{20}$ while other studies have shown either no effect ${ }^{16}$ or a lower completion rate. ${ }^{17,21}$ An encouraging finding is that AAS graduates are transferring to baccalaureate programs at increasing rates. ${ }^{16}$

\section{Transfer Credits}

Two overall strategies for facilitating career pathways involve improving the number of degree credits that transfer directly to $4-y$ institutions and articulation agreements. ${ }^{22}$ The ease of transfer to 4-y institutions is a critical juncture for attaining a bachelor's degree.23-25 Structural barriers between $2-y$ and 4-y institutions ${ }^{23,26}$ and the absence of articulation policies can make the transfer process difficult. ${ }^{23}$ Usually, 4-y institutions make the sole decision about whether a course will transfer. ${ }^{25}$ This makes collaboration between 2-y and 4-y institutions increasingly important. 


\section{Communication of Career Pathways by Associate Programs}

In this study, only 16 (18\%) of the sample listed college transfer credits somewhere on the Web site. Ideally, states have transfer policies that integrate coursework between 2-y and 4-y institutions. These policies may come in the form of a common course numbering system between $2-y$ and 4-y institutions, having 2-y institutions serve as a branch campus to a flagship public university, or a coordinating board for a state's public and private universities. ${ }^{20}$ Transfer policies minimize the need for students to retake courses after transfer, which decreases the expense and the amount of time needed to complete a bachelor's degree. ${ }^{27}$ Students who are required to take more courses as part of an inefficient transfer process may run out of financial aid if credit accumulation is too high. ${ }^{26} \mathrm{~A}$ baccalaureate degree requires 100-130 total credits at most universities. When associate degree students accumulate 80-90 credits, they should be $60 \%$ of the way toward their degree. However, they often are not and students run out of institutional aid. ${ }^{28}$ Transfer systems should be efficient enough for students to find information easily, so they can take full advantage of their opportunities and minimize the risk of dropout.

\section{Articulation Agreements}

Articulation agreements smooth the transfer process by allowing a block of credits to transfer. This eliminates the need for 4-y institutions to evaluate each course individually for acceptance. ${ }^{18}$ Furthermore, the process is more transparent for the student. These articulation agreements can take many forms. The agreement can form between a 2-y college and a 4-y system, between a 2-y college system and a 4-y college system, or among individual programs and a 4-y college or college system. ${ }^{18}$

The impact of statewide articulation policies had no effect on enrollment in a study that examined students enrolling in 2-y institutions in 1994 across 49 states. This may have resulted from the systems not fully implementing their process or adequately communicating them to students. ${ }^{16}$ More recent data showed similar results in that there is wide variation in transfer outcomes across states..$^{29}$ Limited information about the transfer process and the lack of coordination between 2-y and 4-y institutions are barriers to degree completion. ${ }^{26}$ Transfer implies a partnership. ${ }^{25}$ It takes strong collaboration, communication, and mutual respect between 2-y and 4-y institutions to foster these agreements. The students, institutions, and broader community all benefit. ${ }^{18}$

In this study, only $29 \%$ of the sample listed an articulation agreement. For those that did, $24 \%$ of agreements were hidden in a subfolder and were difficult to find; only a few were easily visible on the Web site. Thus, in addition to having articulation agreements in place, the information needs to be clearly communicated to prospective students and graduates. This presents an opportunity for both the respiratory program and degree advancement programs that offer baccalaureate completion options. The public listing of an articulation agreement provides an inexpensive marketing tool for both program types.

\section{Development and Dissemination of RT Career Pathways}

To achieve the respiratory care profession's goal of increasing the number of RTs holding a baccalaureate degree, associate degree graduates need career pathways tailored to their needs. As early as the 1990s there was recognition that the demand for bachelor's degrees for applied or practical skills was needed. Proprietary schools led the way in creating programs to fill the void for AAS transfer students. ${ }^{30}$ Characteristics of a single-degree completion program designed for AAS students $(n=339,68 \%$ response rate) demonstrated that $70 \%$ had worked $\geq 11 \mathrm{y}$ since high school graduation and $76 \%$ worked $\geq 40 \mathrm{~h} / \mathrm{wk}$. Thus, distance education or online programming was critical to provide access for these students. In addition, 54\% of employers provided some type of financial assistance for their employees. ${ }^{7}$

Fortunately, the respiratory care education community has 2 advocacy groups that can facilitate the development of these pathways. The National Association of 2-Year Respiratory Care programs (NA2RC), formerly NN2RC, promotes the role of associate degree programs and career pathways. A second group, the Committee on Baccalaureate and Graduate Respiratory Therapy Education (CoBGRTE) promotes baccalaureate and graduate respiratory care education. The respective organizations' vision and objective highlight these similar goals:

- NA2RC Vision: To confirm the role of the associate degree for entry into the respiratory care educational and career pathways. (http://www.nn2rc.org/new-aboutus.html, Accessed December 17, 2017).

- CoBGRTE Objective: Assist associate degree respiratory therapy programs in developing consortium and transfer agreements with colleges offering baccalaureate and graduate degrees. (http://www.cobgrte.org/, Accessed December 17, 2017).

After pathways are established, institutions need to clearly articulate them to students to avoid surprises or problems. ${ }^{22,31}$ Both 2-y and 4-y institutions have the responsibility to motivate students along the career pathway. ${ }^{17}$ Two-year institutions need to provide the transfer curriculum and clearly communicate the pathway. A recent evaluation of how well 2-y institutions serve their transfer students indicated that transfer rate is directly related to service. ${ }^{29}$ Four-year institutions need to facilitate 


\section{Communication of Career Pathways by Associate Programs}

during the transition phase to simplify the process. ${ }^{31}$ Furthermore, employers need to become aware of programs to help encourage employees to continue their education. ${ }^{7}$

Although career pathways smooth the journey to complete a baccalaureate degree, market demand will influence the number of RTs who earn baccalaureate degrees. It is not known how many RTs believe that having a baccalaureate degree is important or are aware of the AARC's goal for $80 \%$ of RTs to hold or be working toward a baccalaureate degree by 2020 . Employers also have a critical stake in this conversation. When employers demand baccalaureate degrees, both RTs and academic institutions will be forced to respond. Thus, engaging employers in this discussion is essential for any significant changes in the rates of RTs earning bachelor's degrees. Licensing agencies may also play a role. For example, in the state of New York, nurses who graduate without a baccalaureate degree have $10 \mathrm{y}$ to earn one or risk losing their license to practice. ${ }^{32}$

\section{Type of Baccalaureate Degree}

Another variable for AAS graduates to consider is the type of baccalaureate degree to pursue. One pathway to a baccalaureate degree is the Bachelor of Applied Science (BAS) degree. This degree emerged in the $1970 \mathrm{~s}^{33}$ and prepares individuals for either advanced technical practice or managerial roles through an inverted academic pattern in which the discipline-specific content occurs first, and the general education comes later. These degrees have a greater focus on workplace competencies and not on traditional preparation for graduate school. ${ }^{34}$ As such, individuals wishing to pursue a graduate degree should carefully explore transfer requirements to prepare for future admission requirements. Numerous 2-y institutions offer the Bachelor of Applied Science. These institutions offer the advantage of being less expensive, local, and responsive to employer demands. ${ }^{35}$

\section{Limitations}

This study had a number of limitations. A sample was used rather than conducting a complete census. However, the sample was representative for the proportions of AS versus AAS programs and regional distribution. This study solely evaluated program Web site information. Thus, the study results do not reflect the communications that faculty gave their students and graduates about pursuing baccalaureate degrees. It is also possible that information related to bachelor's degree was present on the Web sites but was not identified. Most information about bachelor's degree appeared in subfolders, so some data may have been missed despite the independent review by 2 researchers.

\section{Conclusions}

This study focused on how well the Web sites for AS and AAS degree programs relayed information about completing bachelor's degrees. The findings suggest that RT programs have not maximized their ability to provide associate degree graduates with a career pathway to a bachelor's degree. An overwhelming majority of program Web sites did not contain information on either of the 2 methods identified in the literature (ie, transfer credits and articulation agreements), that facilitate completion of bachelor's degrees. Prospective, current, and former RT students would all benefit from concise, clear, and transparent information about bachelor's degrees. Associate and baccalaureate degree programs must collaborate with each other to facilitate the baccalaureate completion. This will hopefully ease the path for RTs to obtain the advanced education required to serve all phases of their careers.

\section{REFERENCES}

1. Barnes TA, Black CP, Douce EH, LeGrand TS, Morfei JJ, Nilsestuen JO, et al. Development of baccalaureate and graduate degrees in respiratory care: a white paper from the AARC steering committee of the coalition for baccalaureate and graduate respiratory therapy education. Respir Care Education Annual 2003;12:29-39.

2. Kacmarek RM, Durbin CG, Barnes TA, Kageler WV, Walton JR, O'Neil EH. Creating a vision for respiratory care in 2015 and beyond. Respir Care 2009;54(3):375-389.

3. Barnes TA, Gale DD, Kacmarek RM, Kageler WV. Competencies needed by graduate respiratory therapists in 2015 and beyond. Respir Care 2010;55(5):601-616.

4. Barnes TA, Kacmarek RM, Kageler WV, Morris MJ, Durbin CG. Transitioning the respiratory therapy workforce for 2015 and beyond. Respir Care 2011;56(5):681-690.

5. Commission on Accreditation for Respiratory Care. 2016 report on accreditation in respiratory care education. Bedford, Texas: CoARC; 2017.

6. Aiken L, Clarke S, Cheung R, Sloane D, Silber J. Educational levels of hospital nurses and surgical patient mortality. JAMA 2003;290(12): 1617-1623.

7. Batts DL, Pagliari LR. Transforming the terminal associates of applied science into a four-year degree: a win-win situation for students, community colleges, universities, and businesses. Community College J Research Pract 2013;37(5):365-373.

8. Committee on Accreditation for Respiratory Care. Outcomes data from 2015 CoARC annual report of current status (RCS) for entry into respiratory care professional practice programs. Bedford, Texas: CoARC; $2016: 7$.

9. American Association for Respiratory Care. AARC respiratory therapist human resource study 2014. Irving, Texas: AARC; 2014.

10. Grubb WN. The decline of community college transfer rates: evidence from national longitudinal surveys. J Higher Educ 1991;62(2): 194-222.

11. Bailey T, Jenkins D, Leinbach DT. Is student success labeled institutional failure? Student goals and graduation rates in the accountability debate at community colleges. Community College Research Center Working Paper No. 1; 2005.

12. Horn L, Skomsvold P. Community college student outcomes: 1994 2009. National Center for Education Statistics 2011;NCES 2012253:1-48. 


\section{Communication of Career Pathways by Associate Programs}

13. Mullin CM. Rebalancing the mission: the community college completion challenge. American Association of Community Colleges Policy Brief 2010-02PBL. Washington, DC: ERIC; 2010:1-10.

14. Barreno Y, Traut CA. Student decisions to attend public two-year community colleges. Community College J Research Pract 2012; 36(11):863-871

15. American Association of Community Colleges. The associate degree. AACC Policy Statement; 1998.

16. Roksa J. Does the vocational focus of community colleges hinder students' educational attainment? Rev Higher Educ 2006;29(4):499-526.

17. Kopko E, Crosta P. Should community college students earn an associate degree before transferring to a 4-year institution? Res Higher Educ 2016;57(2):190-222.

18. Zinser RW, Hanssen CE. Improving access to the baccalaureate: articulation agreements and the National Science Foundation's advanced technological education program. Community College Rev 2006;34(1):27-43.

19. Gawenda PB. Terminating terminal associate degree programs: giving manual intelligence an academic chance. Community College $\mathrm{J}$ Research Pract 2004;28(1):45-46.

20. Ehrenberg RG, Smith CL. Analyzing the success of student transitions from 2-to 4-year institutions within a state. Econ Educ Rev 2004;23(1):11-28

21. Alfonso M, Bailey TR, Scott M. The educational outcomes of occupational sub-baccalaureate students: evidence from the 1990s. Econ Educ Rev 2005;24(2):197-212.

22. Hu X, Ortagus JC, Kramer DA. The community college pathway: an analysis of the costs associated with enrolling initially at a community college before transferring to a 4-year institution. Higher Educ Policy 2017, doi: 10.1057/s41307-017-0063-7.

23. Roksa J, Calcagno JC. Catching up in community colleges: academic preparation and transfer to four-year institutions. Teachers College Record 2010;112(1):260-288.
24. Laanan FS. Studying transfer students. part ii: dimensions of transfer students' adjustment. Community College J Research Pract 2007;31(1):37-59.

25. Handel SJ. Community college students earning the baccalaureate degree. College University 2013;89(2):22.

26. Long BT, Kurlaender M. Do community colleges provide a viable pathway to a baccalaureate degree? Educ Eval Policy Analysis 2009; 31(1):30-53.

27. The National Center for Public Policy and Higher Education. Affordability and transfer: critical to increasing baccalaureate degree completion. San Jose, California: The National Center for Public Policy and Higher Education; 2011.

28. Smith AA. Two-year transfers are finding not all of their credits go with them. Inside Higher Ed: Jun 8, 2015. https://www.insidehighered.com/news/2015/06/08/two-year-transfers-are-finding-not-alltheir-credits-go-them Accessed Feb 2, 2018.

29. Jenkins D, Fink J. Tracking transfer: new measures of institutional and state effectiveness in helping community college students attain bachelor's degrees. New York: Community College Research Center, Teachers College, Columbia University; 2016.

30. Bender LW. Applied associate degree transfer phenomenon: proprietaries and publics. Community College Rev 1991;19(3):22-28.

31. Melguizo T, Kienzl GS, Alfonso M. Comparing the educational attainment of community college transfer students and four-year college rising juniors using propensity score matching methods. J Higher Educ 2011;82(3):265-291.

32. A1842-B. Assemb. Reg. Sess. 2017-2018. (N.Y. 2018).

33. Townsend BK, Bragg DD, Ruud CM. Development of the applied baccalaureate. Community College J Research Pract 2009;33(9):686705 .

34. Wallace SR. Meeting the needs of information-age employers. Community College J 1999;69(6):21-22.

35. Walker KP. Opening the door to the baccalaureate degree. Community College Rev 2001;29(2):18-28.

This article is approved for Continuing Respiratory Care Education credit. For information and to obtain your CRCE

(free to AARC members) visit www.rcjournal.com 